\title{
Release and Activity of Anti-TNFa Therapeutics from Injectable Chitosan Preparations for Local Drug Delivery
}

\author{
Mohammed F. Shamji, M.D., Ph.D. ${ }^{1,2}$, Priscilla Hwang, B.S. ${ }^{1}$, Robert W. Bullock, B.S. ${ }^{1}$, \\ Samuel B. Adams Jr., M.D. ${ }^{3}$, Dana L. Nettles, Ph.D. ${ }^{1}$, and Lori A. Setton, Ph.D. ${ }^{1,3}$ \\ ${ }^{1}$ Department of Biomedical Engineering, Duke University, Durham, NC \\ 2Division of Neurosurgery, The Ottawa Hospital, Ottawa, ON \\ ${ }^{3}$ Division of Orthopedic Surgery, Duke University Medical Center, Durham, NC
}

\begin{abstract}
Background-Tumor necrosis factor alpha $(\mathrm{TNF} \alpha)$ is a cytokine that regulates immune and inflammatory overactivation in various pathological states. Protein therapeutics may antagonize this cytokine, but may also have systemic toxicities. Small molecule natural products are also efficacious, but can suffer from poor oral bioavailability. A drug delivery vehicle is needed to sustain release of active therapeutics and address localized inflammation.
\end{abstract}

Materials-Chitosan is a biocompatible aminopolysaccharide that undergoes thermally-initiated gelation in cosolutions with glycerophosphate (GP), and may entrap and sustain release of additive therapeutics. Gelation time and temperature of chitosan/GP were evaluated by turbidity $\left(\mathrm{OD}_{350}\right)$, as was the kinetic effect of bovine serum albumin (BSA) entrapment. We investigated in vitro release of BSA and various anti-TNF agents (curcumin, sTNFRII, anti-TNF antibody) and confirmed in vitro activity of the released drugs using an established bioassay.

Results-Turbidity results show that chitosan/GP thermogel achieves gelation at $37^{\circ} \mathrm{C}$ within 10 minutes, even with significant protein loading. Sustained BSA release occurred with $50 \%$ retained at 7 days. All anti-TNF therapeutics exhibited sustained release, with $10 \%$ of sTNFRII and antiTNF antibody remaining after 7 days and $10 \%$ of curcumin remaining after 20 days. After release, each compound antagonized TNF $\alpha$-cytotoxicity in murine fibrosarcoma cells.

Conclusions-This study demonstrates that thermogelling chitosan/GP entraps and sustains release of a broad range of anti-TNF agents. Such delivery of disease-modifying therapy could establish a drug depot to treat local inflammation. The breadth of molecular sizes demonstrates significant versatility, and slow release could protect against toxicities of systemic delivery.

\section{Keywords}

chitosan; drug delivery; drug depot; tumor necrosis factor alpha; inflammation; curcumin

\section{Introduction}

Tumor necrosis factor alpha (TNF $\alpha)$ is a potent cytokine involved in immune and inflammatory function and has been implicated in multiple pathological conditions. Upon binding to target transmembrane receptors, TNF $\alpha$ initiates cytotoxic or proinflammatory signaling cascades, dissociated by target cell type and receptor population.1 Disease-

Reprint Author, Lori A. Setton Ph.D., Department of Biomedical Engineering, 136 Hudson Hall, Box 90821, Duke University, Durham, NC 27708 USA, Phone: (919) 660-5131, Fax: (919) 681-8490, setton@ duke.edu. 
modifying, anti-TNF $\alpha$ compounds have been successful in antagonizing the activity of this cytokine providing for effective treatment of psoriasis, Crohn's disease, $2^{-} 4$ ankylosing spondylitis,5,6 psoriatic arthritis, 7,8 rheumatoid arthritis, 9 lumbar radiculopathy 10 and ulcerative colitis. 11 Anti-TNF $\alpha$ antibodies and soluble TNF receptor cleavage products are high affinity TNFo-binding proteins that sequester the cytokine away from the target cell to prevent downstream activation. Side effects of such immunosuppressive therapy include heightened risk of infection and non-Hodgkin's lymphoma, reactivation of latent tuberculous disease, and generation of autoreactive and neutralizing antibodies.12- 15 Current local delivery strategies to eliminate this toxicity include intra-articular delivery of infliximab for rheumatoid arthritis to provide for high dosing at the pathological site 16 and an ongoing clinical trial of epidural etanercept for the biochemical inflammatory component of lumbar radiculopathy. 17 Nevertheless, rapid drug clearance and high systemic exposure still remain as significant concerns. Curcumin is a low molecular weight TNF $\alpha$ antagonist that has effects on NFKB signaling, with safety in humans at oral doses of $8 \mathrm{~g}$ per day and achieving active colorectal tissue concentrations for the treatment of ulcerative colitis.18,19 However, curcumin has limited bioavailability after systemic redistribution, 19 limiting effectiveness outside the enteric compartment through oral administration. While topical application of curcumin is described for treating scleroderma, psoriasis, and cutaneous malignancy,20 local delivery to treat internal sites of inflammation remain uncharacterized. There is clear interest developing injectable strategies to locally sustain delivery of bioactive anti-TNF $\alpha$ therapeutics and treat monoarticular rheumatoid arthritis, osteoarthritis, radiculopathy, gout, and other locally-confined inflammatory pathologies.

In situ thermogelling materials may be used for minimally-invasive injection delivery to form local drug depots for sustained release.21 Thermally-triggered gelation at physiological temperature may permit entrapment of co-administered therapeutics, and sustain their release by slowed drug diffusion and/or polymer dissolution. Various carriers evaluated for this purpose include copolymers of polyethylene oxide and polypropylene oxide (polaxamer), poly-N-isopropylacrylamide (poly-NIPAAm), elastin-like polypeptides (ELPs), triblock copolymers of poly(lactic-co-glycolic acid) (PLGA) and polyethylene glycol (PEG), and xyloglucan.22,23 Polaxamers demonstrate an inverse phase transition at high concentrations (between 20 and 30\%) and sustain release of entrapped therapeutics including interleukin-2,24 bone morphogenetic protein, 25 and urease 26 in the short term, but they are non-biodegradable and cause hypercholesterolemia and hypertriglyceridemia upon in vivo administration in mice 27 and rats28. Introduction of biodegradable functionality with block copolymers of polyethylene oxide and poly-[(R)-3-

hydroxybutarate] also sustains in vitro release of fluorescein isothiocyanate labeled dextrans upon polymer complexation with cyclodextrin.29 Similarly, poloxamers with oligolactide spacers sustain release of human growth hormone, though protein activity following release remains uninvestigated.30 Poly-NIPAAm exhibits a soluble to gel transition at subphysiologic temperature, and copolymers with monomers of diverse functionality can introduce hydrophobic, $\mathrm{pH}$ sensitive, cross-linkable, or conjugation domains to enhance drug entrapment and sustain release. Examples include sustained release of streptokinase and heparin from poly(NIPAAm-co-methacrylic acid) hydrogels,31 and insulin from poly(NIPAAm-co-butylmethacrylate-co-acrylic acid) beads with hypoglycemia in animal models.32 Such systems have limited biodegradability, and observed in vitro cytotoxicity may restrict in vivo application.33 ELPs are recombinant biopolymers that form depots at tunable transition temperatures and subsequently slowly resolubilize. ELP conjugates with bioactive domains exhibit bivalent functionality, $34^{-} 37$ although lower bioactivity for conjugates than the parent compound may reflect steric inaccessibility of the drug domain. 36,37 The triblock PLGA-PEG-PLGA has been evaluated for sustained release of chemotherapeutics, but has also demonstrated sustained release of larger protein molecules including granulocyte colony stimulating factor,38 insulin,38 porcine growth hormone,38 
and interleukin-2.39 Xyloglucan is a natural polysaccharide that undergoes gelation at room temperature at low concentrations between 1 and $2 \%$. It successfully sustains the in vivo release of small molecules in animal studies such as rectal delivery of indomethacin, 40 retinal delivery of pilocarpine, 41 and topical application of ibuprofen.42 Biocompatibility of this polymer is uncertain, and applications to larger therapeutics remain unexplored.

Chitosan is an aminopolysaccharide that is insoluble at physiological $\mathrm{pH}$, but can be solvated in the presence of a polyol anion, $\beta$-glycerophosphate.43,44 These cosolutions undergo thermally-triggered gelation upon heating and may hence entrap therapeutic molecules. Polyol anion stabilization of polycation chitosan inter-chain interaction drives this process, potentiating hydrophobic interactions and hydrogen bonding.44,45 At cool temperature, chitosan solvation by water prevents aggregation; however heating removes these sheaths of water permitting association of discrete chitosan molecules. Chitosan is rapidly cleared after intraperitoneal injection in animals, but thermogels remain intact for days to weeks allowing subcutaneous injection. 45 Bovine serum albumin 44 and bone morphogenetic protein 46 are examples of sustained protein release, with other smaller molecules evaluated in this system including paclitaxel, chlorpheniramine, and methylene blue. 47

A need exists for a local drug delivery system that can combine ease of anticytokine drug loading with the capability of sustaining therapeutic release over a prolonged period of time. The primary objective of this study was characterizing in vitro release and bioactivity of BSA and various anti-TNF $\alpha$ agents following entrapment and release from a chitosan-GP gel. The TNF $\alpha$-antagonists investigated were curcumin $(\mathrm{MW}=369 \mathrm{Da})$, soluble TNF receptor Type II (sTNFRII, MW=18.9 $\mathrm{kDa}$ ), and a monoclonal anti-TNF $\alpha$ antibody $(\mathrm{MW}=150 \mathrm{kDa}$ ). A second objective was characterizing the effect of protein loading on gelation kinetics of chitosan-GP, through studies with varying BSA concentration.

\section{Methods}

\section{Preparation of Thermogels}

Chitosan (Sigma-Aldrich, St. Louis, MO) was prepared as a 2\% aqueous solution dissolved in $0.1 \mathrm{M}$ acetic acid at $4^{\circ} \mathrm{C}$. An aqueous solution of $45 \% \beta$-glycerophosphate (GP) was added in a dropwise fashion to a final volume ratio of 1:3. This solution remained fluid at subphysiologic temperature, and volumes of $1 \mathrm{~mL}$ were used to evaluate kinetics of gelation as well as sustained therapeutic release as described below. Gelation was thermallytriggered by raising the temperature of the solution to physiologic temperature.

\section{Gelation Kinetics}

The kinetics of chitosan-GP gelation were evaluated as a function of entrapped protein concentration using two methods. The turbidity of $1 \mathrm{~mL}$ chitosan-GP solutions loaded with varying amounts of BSA ( $0 \mathrm{mg}$ to $3.75 \mathrm{mg}$ ) was measured as the time-dependent change in optical density at $350 \mathrm{~nm}$ (OD350, Cary-UV-Vis Spectrophotometer, Varian, Walnut Creek, CA). The analyzed solution was initially at $4^{\circ} \mathrm{C}$ and then placed in a cuvette-holder held at $37^{\circ} \mathrm{C}$, and the gelation time recorded as the point when the OD350 increased by $50 \%$ of the maximum observed change.

Gelation time was also recorded for each sample by a "gel-tipping method" 48 of horizontal tipping of a cuvette and grossly observing for cessation of flow. Briefly, the cuvette containing chitosan-GP with a desired amount of BSA $\left(n=4\right.$ per dose), initially at $4^{\circ} \mathrm{C}$, were held at $37^{\circ} \mathrm{C}$ and tipped horizontally at one minute intervals during this transition to evaluate whether the material was grossly observed to flow or not. One-way ANOVA with 
post-hoc Dunn's analysis ( $\alpha=0.05$ level of significance) was used to evaluate differences in gelation time as a function of mass of BSA loaded.

\section{Drug Release}

Chitosan-GP gels of $1 \mathrm{~mL}$ volume were prepared as described above with the addition of $750 \mu \mathrm{g}$ BSA (Sigma-Aldrich, St. Louis, MO, $\mathrm{n}=8$ ), $1 \mu \mathrm{g}$ sTNFRII (Abcam, Cambridge, MA, $n=4$ ), $8 \mu \mathrm{g}$ anti-TNF $\alpha$ antibody (Abcam, Cambridge, MA, $\mathrm{n}=4$ ), or $25 \mu \mathrm{g}$ curcumin (Sigma-Aldrich, St. Louis, MO, $n=5$ ). Following thermally-triggered gelation, the drugloaded gels were immersed in PBS that was withdrawn and replaced every 24 hours to maintain dilute conditions for the overlying supernatant. Collection of the media every 24 hours also provided for equal sampling intervals throughout. Release of BSA was evaluated by the bicinchoninic acid (BCA) assay. Release of sTNFRII was estimated by a sandwich enzyme linked immunosorbent assay (R\&D Systems, Minneapolis, MA) and release of the anti-TNF $\alpha$ antibody was quantified by a TNF $\alpha$-directed ELISA. A similar methodology was used for curcumin release, except into overlying PBS with $0.1 \%$ Triton-X as previously described.49 Curcumin concentrations were quantified by optical density at $426 \mathrm{~nm}$ using absorbance spectrophotometry. Further, supernatant from control chitosan-GP gels without entrapped agents were used to assess background signals in each assay. The protein amounts released into supernatant was normalized by total loaded protein in order to determine the fractional release of each anti-TNF $\alpha$ therapeutic and BSA over time.

\section{Determination of Release Kinetics}

Curcumin release from chitosan-GP hydrogels were fit to a one-dimensional unsteady diffusion model. This was not performed for the larger protein therapeutics that were entrapped as previous work by Ruel-Gariepy and coworkers44 has demonstrated some potential for carrier-drug interaction leading to more complex release profiles. The solution to a one-dimensional diffusion model with assumptions of unsteady release and an infinite and dilute external bath is adapted from work by Truskey and coworkers50:

$$
x(t)=\left(1-\sum_{n=0}^{\infty} \frac{8}{\pi^{2}(2 n+1)^{2}} e^{-\frac{(2 n+1)^{2} t}{\tau}}\right)\left(1-x_{0}\right)+x_{0}
$$

where $\mathrm{x}(\mathrm{t})$ is the fractional amount of drug released to the overlying bath at time ' $\mathrm{t}$ ', $\mathrm{x}_{0}$ is the initial fraction of drug found in the supernatant at time 0 , and $\tau$ is a characteristic time constant of release. Observations for cumulative curcumin release were fit to this model using non-linear least squares regression (fmincon, constrained optimization, MATLAB, MathWorks, Natick, MA).

\section{In vitro Bioassay of Drug Functionality}

Murine fibrosarcoma L929 cells (ATCC, Rockville, MD) were grown in $75 \mathrm{~cm}^{2}$ tissue culture flasks containing culture medium (DMEM supplemented with $10 \%$ horse serum, 4.5 $\mathrm{g} / \mathrm{L}$ glucose, $50 \mathrm{U} / \mathrm{mL}$ penicillin, and $50 \mu \mathrm{g} / \mathrm{mL}$ streptomycin). Cells were incubated for 24 hours in a 96-well plate at density of 10000 cells/well in $70 \mu \mathrm{L}$ of culture medium. Cells were sensitized to cytotoxicity using actinomycin $\mathrm{D}(1 \mu \mathrm{g} / \mathrm{mL})$ for one hour, after which $0.25 \mathrm{ng} / \mathrm{mL} \mathrm{TNF} \alpha$ was introduced. In a parallel set of drug release experiments, curcumin, sTNFRII, and anti-TNF $\alpha$ antibody were released into overlying PBS for 14 days without supernatant replacement to achieve bioactive concentrations. Antagonism of TNF $\alpha$-induced cytotoxicity involved concomitant treatment $(n=8)$ with the released BSA, curcumin, sTNFRII, or anti-TNF antibody to demonstrate cytoprotection. The assay plate was incubated for a further 24 hours after which cell survival was quantified by the CellTiter Glo 
luminescence assay (Promega, Madison, WI). Treatment effects were normalized against the observed survival of cells without introduction of TNFa. One-way ANOVA with post-hoc Dunn's analysis ( $\alpha=0.05$ level of significance) was used to evaluate differences in fractional cell survival time as a function of treatment with the released therapeutics.

\section{Results}

\section{Gelation Kinetics}

Gelation kinetics were evaluated by both onset of turbidity at $37^{\circ} \mathrm{C}$ and absence of flow in the gel tipping method. Figure 1A demonstrates that the onset of gelation by turbidity analysis occurred at between 13 and 15 minutes for chitosan-GP alone, with no apparent difference in gelation kinetics with incorporation of up to $3.75 \mathrm{mg}$ BSA. In contrast to this observation, Figure 1B illustrates that the gel tipping study yielded results where the time to loss of flowing behaviors steadily increased with the amount of BSA loaded (ANOVA, $\mathrm{p}<$ 0.01 ). The gelation process for $15 \mathrm{mg}$ chitosan occurred within 5 minutes in the absence of drug, at $13.3 \pm 0.5$ minutes in the presence of $750 \mu \mathrm{g}$ BSA, and $17.0 \pm 0.5$ minutes when $3.75 \mathrm{mg}$ were introduced (Dunn's, $\alpha=0.05$ ).

\section{Drug Release}

Molecular entrapment in the chitosan-GP gel permitted for sustained in vitro release.

Release of BSA was sustained with $50 \%$ of the loaded protein released by 72 hours and $10 \%$ of the protein still remaining in the gel at 200 hours (Figure 2). All anti-TNF therapeutics also exhibited sustained-release with 50\% release times of curcumin at 156 hours (Figure 3A), sTNFRII at 84 hours (Figure 3B), and anti-TNF antibody at 108 hours (Figure 3C).

\section{Determination of Release Kinetics}

Cumulative curcumin release from chitosan-GP hydrogels was well described by a onedimensional unsteady diffusion model. Characteristic time constants were found to vary from 170 to 263 hours, with a mean $( \pm \mathrm{SD}$ ) value of $230 \pm 40$ hours. The coefficients of determination for these regression trials ranged from 0.91 to 0.97 , and the fit curve for the average data is shown in Figure 3A, superimposed on the experimental data.

\section{In vitro Bioassay of Drug Functionality}

Following therapeutic release from the chitosan-GP gels, each therapeutic was observed to retain in vitro anti-TNF bioactivity (Figure 4, ANOVA, $\mathrm{p}<0.01$ ). Effective cytotoxic activity occurred on incubation of fibrosarcoma cells with TNF $\alpha$, with no reversal of this change observed upon coincubation with released BSA. Released curcumin, sTNFRII, and anti-TNF $\alpha$ antibody provided for substantial cell survival reflecting the expected therapeutic activity (Dunn's, $\alpha=0.05$ ).

\section{Discussion}

Local delivery of anti-TNF $\alpha$ compounds may overcome limitations associated with systemic administration when treating inflammatory disease. Both protein therapeutics, sTNFRII and anti-TNF $\alpha$ antibody, bind TNF $\alpha$ and sequester it away from normal target cells. Modifications of TNF-receptors include expression as a fusion protein with an immunoglobulin $\mathrm{Fc}$ domain51 (etanercept) or chemical conjugation with poly(ethyleneglycol)52 (pegsunercept) to increase protein molecular weight and hence retard elimination. Side effects of such therapy include heightened risk of infection and nonHodgkin's lymphoma, reactivation of latent tuberculous disease, and generation of autoreactive and neutralizing antibodies. 12 Curcumin is a natural low molecular weight therapeutic that effects NFKB signaling, but poor systemic bioavailability after oral 
administration has limited its utility.18,19 In this study, thermogelling solutions of polycation chitosan and polyol anion $\beta$-glycerophosphate entrapped and sustained the release of BSA and several anti-TNF therapeutics of variable molecular weights. Favorable release kinetics were observed for all three drugs from the chitosan-GP thermogels, with release kinetics that were not solely dependent on the molecular weight of the entrapped antagonist. Curcumin $(369 \mathrm{Da})$ exhibited 50\% drug release at 180 hours compared to 84 hours for the sTNFRII (18.9 kDa) and 108 hours for the anti-TNF $\alpha$ antibody (150 kDa). The time constants for curcumin release ( $240 \pm 30$ hours) are congruent with previous studies of release from PLGA coated stents,53 poloxamer,54 and copolymer nanoparticles of $\mathrm{N}$ isopropylacryalamide, $\mathrm{N}$-vinyl-2-pyrrolidone, and poly(ethyleneglycol)monoacrylate. 55

Kinetics of protein therapeutic release from the chitosan-GP gels appeared quite different from that of curcumin, with $30 \%$ of the loaded curcumin remaining in the gels at approximately 10 days, as compared to $10 \%$ of the loaded sTNFRII and anti-TNF $\alpha$ antibody remaining in the gels at the same timepoint. While the curcumin release profile was welldescribed by an unsteady diffusion model, the sTNFRII demonstrated an initial plateau, followed by a rapid release phase and subsequent deviation from equilibrium that was not well-described by a diffusion model. These observations may reflect greater diffusivity of the small curcumin molecule or more complicated charge interaction effects between the protein drugs and the polycation chitosan. Such interaction may contribute to enhanced diffusion or accelerated gel dissolution effect for larger molecular weight compounds. Understanding the mechanism of drug release from these gels, along with a model predicting the kinetics of drug release, represents future work of value in determining drug loading doses and concentrations required to achieve in vivo efficacy.

This study reveals that BSA loading affects the kinetics of chitosan-GP gelation, with substantially increased gelation times observed at higher BSA doses $(3.75 \mathrm{mg})$. It is possible that the three different $\mathrm{TNF} \alpha$ antagonists would variably affect gel formation, though the doses evaluated ( $1 \mu \mathrm{g}$ sTNFRII, $8 \mu \mathrm{g}$ anti-TNF $\alpha$ antibody, $25 \mu \mathrm{g}$ curcumin) were much lower than those BSA doses that prolonged gelation time. Additional studies varying antagonist loading dose into the chitosan-GP gels may further reveal the mechanisms governing gel formation kinetics and the mechanisms for drug release. Furthermore, an upper limit may exist on the amount of drug that can be loaded into this system while maintaining rapid, clinically-feasible gelation. This limit likely depends on the ionic nature and molecular weight of the therapeutic. Larger and polycationic drugs may interfere more significantly with thermogel stability, manifest in more limited loading. Ganji and coworkers 48 have demonstrated that altering the degree of chitosan deacetylation and the concentration of glycerophosphate coslolute also affect gelation time. Nevertheless, the chitosan-GP gels in this study were observed to form and entrap as much as $3.75 \mathrm{mg}$ BSA for $15 \mathrm{mg}$ chitosan, suggesting possibility to entrap and release clinically relevant doses of many protein therapeutics.

Anti-TNF $\alpha$ activity was observed for all three therapeutics following release from the chitosan-GP delivery vehicle. Furthermore, the chitosan-GP alone or loaded with BSA did not alter survival of L929 fibrosarcoma cells after TNF $\alpha$ stimulation, suggesting that the anti-TNF compounds were responsible for the observed cytoprotection. These findings are similar to other studies reporting in vitro culture of established cell lines (cos-7, L929, and Rat-1) and primary bovine and human chondrocytes.45 Chitosan-GP persists for several weeks following subcutaneous implantation in mice, 45 although transient edema has been described upon injection of this material into the rat hindpaw.56 Such a reaction could be minimized by systemic pretreatment with dexamethasone or by using chitosan with higher degrees of deacetylation. Nevertheless, incorporation of osteoinductive proteins into the chitosan-GP hydrogel promotes ectopic calcification at sites of implantation, 45 reaffirming 
both in vivo accessibility and activity of the delivered therapeutics. Our data support these findings with entrapped protein therapeutics exhibiting in vitro anticytokine activity following release from the delivery vehicle.

Local drug delivery applications of chitosan-based therapeutics require consideration of the compartment contents into which the material is being delivered. This is particularly true of in situ forming preparations where fluid composition may impact on the ability of the depot to form, as well as of the efficiency of therapeutic entrapment. Preformed cross-linked chitosan nanoparticles have been previously evaluated for intra-articular delivery of celecoxib with evidence of sustained release and no observed inflammatory response to the vehicle without drug.57 Our proposed application of in situ gelation would require an appropriate microenvironment, with the neutral $\mathrm{pH}$ of the synovial fluid suitable for such application as the acidified chitosan is neutralized with glycerophosphate prior to thermallytriggered gelation. Intra-articular delivery of acidic chitosan solutions ( $\mathrm{pH} 4.05$ ) has been shown to be deleterious in vivo by provoking fibrous tissue formation and cartilage destruction, although more physiological solutions may promote articular chondrocyte proliferation.58 Such findings have led to application of chitosan-based scaffolding biomaterials in cartilage tissue engineering, more extensively reviewed elsewhere.59 Based on the results of work presented herein, the high protein content in the synovial fluid may affect chitosan-GP gelation time, and in vivo pharmacokinetic evaluation of drug distribution would help address questions about entrapment efficiency and sustained release in local compartments of interest.

In summary, thermogelling preparations of chitosan and $\beta$-glycerophosphate entrap and sustain the release of a broad range of molecular weight anti-TNF $\alpha$ agents. When protein was loaded into these thermogels at up to a one-to-four mass ratio, gelation still occurred in a clinically-relevant period of time. Furthermore, upon release from these hydrogels, anti$\mathrm{TNF} \alpha$ activity was preserved for these therapeutics. Injectable delivery of potent immunomodulating therapeutics entrapped in thermogelling chitosan-GP has the benefit of establishing a local drug depot to treat local inflammation, while minimizing systemic exposure and associated immunosuppression. This approach may impact the clinical treatment of many local inflammatory pathologies, including such diseases as monoarticular rheumatoid arthritis, osteoarthritis, disc-herniation radiculopathy, and gout. The broad range of molecular sizes evaluated herein demonstrates the versatility of chitosan-GP to entrap many types of therapeutics, and the slow and sustained release into a targeted compartment could provide for effective local doses and protection against associated toxicities of systemic delivery.

\section{Acknowledgments}

Supporting Grants

NIH R01EB002263 (LAS)

NIH R21AR052745 (LAS)

Pratt-Gardner Predoctoral Research Fellowship (MFS)

\section{References}

1. Barbara JA, Smith WB, Gamble JR, Van Ostade X, Vandenabeele P, Tavernier J, Fiers W, Vadas MA, Lopez AF. Dissociation of TNF-alpha cytotoxic and proinflammatory activities by 555 receptor- and p75 receptor-selective TNF-alpha mutants. EMBO J. 1994; 13(4):843-850. [PubMed: 7509279] 
2. Akobeng AK, Zachos M. Tumor necrosis factor-alpha antibody for induction of remission in Crohn's disease. Cochrane Database Syst Rev. 2004; (1):CD003574. [PubMed: 14974022]

3. Ghosh S. Anti-TNF therapy in Crohn's disease. Novartis Found Symp. 2004; 263:193-205. discussion 205-18. [PubMed: 15669643]

4. Travers SB. Etanercept for Crohn's disease. N Engl J Med. 2004; 350(8):840. author reply 840. [PubMed: 14973205]

5. Hoy SM, Scott LJ. Etanercept: a review of its use in the management of ankylosing spondylitis and psoriatic arthritis. Drugs. 2007; 67(17):2609-2633. [PubMed: 18034593]

6. Wailoo A, Bansback N, Chilcott J. Infliximab, etanercept and adalimumab for the treatment of ankylosing spondylitis: cost-effectiveness evidence and NICE guidance. Rheumatology (Oxford). 2008; 47(2):119-120. [PubMed: 18208819]

7. Adisen E, Karaca F, Gurer MA. When there is no single best biological agent: psoriasis and psoriatic arthritis in the same patient responding to two different biological agents. Clin Exp Dermatol. 2008; 33(2):164-166. [PubMed: 18257837]

8. Saad AA, Symmons DP, Noyce PR, Ashcroft DM. Risks and benefits of tumor necrosis factor-alpha inhibitors in the management of psoriatic arthritis: systematic review and metaanalysis of randomized controlled trials. J Rheumatol. 2008; 35(5):883-890. [PubMed: 18381787]

9. Moreland LW. Tumor necrosis factor inhibitors: new options for treating rheumatoid arthritis. Isr Med Assoc J. 2001; 3(9):686-690. [PubMed: 11574988]

10. Genevay S, Stingelin S, Gabay C. Efficacy of etanercept in the treatment of acute, severe sciatica: a pilot study. Ann Rheum Dis. 2004; 63(9):1120-1123. [PubMed: 15115710]

11. Cottone M, Mocciaro F, Modesto I. Infliximab and ulcerative colitis. Expert Opin Biol Ther. 2006; 6(4):401-408. [PubMed: 16548766]

12. Scheinfeld N. A comprehensive review and evaluation of the side effects of the tumor necrosis factor alpha blockers etanercept, infliximab and adalimumab. J Dermatolog Treat. 2004; 15(5): 280-294. [PubMed: 15370396]

13. Dinarello CA. Differences between anti-tumor necrosis factor-alpha monoclonal antibodies and soluble TNF receptors in host defense impairment. J Rheumatol Suppl. 2005; 74:40-47. [PubMed: 15742464]

14. Ehlers S. Why does tumor necrosis factor targeted therapy reactivate tuberculosis? J Rheumatol Suppl. 2005; 74:35-39. [PubMed: 15742463]

15. Keystone EC. Safety of biologic therapies--an update. J Rheumatol Suppl. 2005; 74:8-12. [PubMed: 15742458]

16. Conti F, Priori R, Chimenti MS, Coari G, Annovazzi A, Valesini G, Signore A. Successful treatment with intraarticular infliximab for resistant knee monarthritis in a patient with spondylarthropathy: a role for scintigraphy with 99mTc-infliximab. Arthritis Rheum. 2005; 52(4): 1224-1226. [PubMed: 15818709]

17. Johns Hopkins University. Efficacy of Epidural Etanercept in the Treatment of Sciatica. ClinicalTrials.gov [Internet]. Bethesda (MD): National Library of Medicine (US); 2006. present. Available from: http://www.clinicaltrials.gov/show/NCT00364572

18. Cheng AL, Hsu CH, Lin JK, Hsu MM, Ho YF, Shen TS, Ko JY, Lin JT, Lin BR, Ming-Shiang W, et al. Phase I clinical trial of curcumin, a chemopreventive agent, in patients with high-risk or premalignant lesions. Anticancer Res. 2001; 21(4B):2895-2900. [PubMed: 11712783]

19. Hsu CH, Cheng AL. Clinical studies with curcumin. Adv Exp Med Biol. 2007; 595:471-480. [PubMed: 17569225]

20. Thangapazham RL, Sharma A, Maheshwari RK. Beneficial role of curcumin in skin diseases. Adv Exp Med Biol. 2007; 595:343-357. [PubMed: 17569219]

21. Hoffman AS. Hydrogels for biomedical applications. Adv Drug Deliv Rev. 2002; 54(1):3-12. [PubMed: 11755703]

22. de Las Heras Alarcon C, Pennadam S, Alexander C. Stimuli responsive polymers for biomedical applications. Chem Soc Rev. 2005; 34(3):276-285. [PubMed: 15726163]

23. Kost J, Langer R. Responsive polymeric delivery systems. Adv Drug Deliv Rev. 2001; 46(1-3): 125-148. [PubMed: 11259837] 
24. Johnston TP, Punjabi MA, Froelich CJ. Sustained delivery of interleukin-2 from a poloxamer 407 gel matrix following intraperitoneal injection in mice. Pharm Res. 1992; 9(3):425-434. [PubMed: 1614979]

25. Clokie CM, Urist MR. Bone morphogenetic protein excipients: comparative observations on poloxamer. Plast Reconstr Surg. 2000; 105(2):628-637. [PubMed: 10697170]

26. Fults KA, Johnston TP. Sustained-release of urease from a poloxamer gel matrix. J Parenter Sci Technol. 1990; 44(2):58-65. [PubMed: 2338605]

27. Palmer WK, Emeson EE, Johnston TP. Poloxamer 407-induced atherogenesis in the C57BL/6 mouse. Atherosclerosis. 1998; 136(1):115-123. [PubMed: 9544738]

28. Wout ZG, Pec EA, Maggiore JA, Williams RH, Palicharla P, Johnston TP. Poloxamer 407mediated changes in plasma cholesterol and triglycerides following intraperitoneal injection to rats. J Parenter Sci Technol. 1992; 46(6):192-200. [PubMed: 1474430]

29. Li J, Li X, Ni X, Wang X, Li H, Leong KW. Self-assembled supramolecular hydrogels formed by biodegradable PEO-PHB-PEO triblock copolymers and alpha-cyclodextrin for controlled drug delivery. Biomaterials. 2006; 27(22):4132-4140. [PubMed: 16584769]

30. Chung HJ, Lee Y, Park TG. Thermo-sensitive and biodegradable hydrogels based on stereocomplexed Pluronic multi-block copolymers for controlled protein delivery. J Control Release. 2008; 127(1):22-30. [PubMed: 18234389]

31. Brazel CS, Peppas NA. Pulsatile local delivery of thrombolytic and antithrombotic agents using poly(N-isopropylacrylamide-co-methacrylic acid) hydrogels. Journal of Controlled Release. 1996; 39(1):57-64.

32. Kim YH, Bae YH, Kim SW. pH/Temperature-Sensitive Polymers for Macromolecular Drug Loading and Release. Journal of Controlled Release. 1994; 28(1-3):143-152.

33. Vihola H, Laukkanen A, Valtola L, Tenhu H, Hirvonen J. Cytotoxicity of thermosensitive polymers poly(N-isopropylacrylamide), poly(N-vinylcaprolactam) and amphiphilically modified poly(N-vinylcaprolactam). Biomaterials. 2005; 26(16):3055-3064. [PubMed: 15603800]

34. Bidwell GL 3rd, Raucher D. Application of thermally responsive polypeptides directed against cMyc transcriptional function for cancer therapy. Mol Cancer Ther. 2005; 4(7):1076-1085. [PubMed: 16020665]

35. Massodi I, Bidwell GL 3rd, Raucher D. Evaluation of cell penetrating peptides fused to elastin-like polypeptide for drug delivery. J Control Release. 2005; 108(2-3):396-408. [PubMed: 16157413]

36. Shamji MF, Betre H, Kraus VB, Chen J, Chilkoti A, Pichika R, Masuda K, Setton LA. Development and characterization of a fusion protein between thermally responsive elastin-like polypeptide and interleukin-1 receptor antagonist: Sustained release of a local antiinflammatory therapeutic. Arthritis Rheum. 2007; 56(11):3650-3661. [PubMed: 17968946]

37. Shamji MF, Chen J, Friedman AH, Richardson WJ, Chilkoti A, Setton LA. Synthesis and Characterization of a Thermally Responsive Tumor Necrosis Factor Antagonist. J Controlled Release. 2008; 129(3):179-186.

38. Zentner GM, Rathi R, Shih C, McRea JC, Seo MH, Oh H, Rhee BG, Mestecky J, Moldoveanu Z, Morgan M, et al. Biodegradable block copolymers for delivery of proteins and water-insoluble drugs. J Control Release. 2001; 72(1-3):203-215. [PubMed: 11389999]

39. Samlowski WE, McGregor JR, Jurek M, Baudys M, Zentner GM, Fowers KD. ReGel polymerbased delivery of interleukin-2 as a cancer treatment. J Immunother. 2006; 29(5):524-535. [PubMed: 16971808]

40. Miyazaki S, Suisha F, Kawasaki N, Shirakawa M, Yamatoya K, Attwood D. Thermally reversible xyloglucan gels as vehicles for rectal drug delivery. J Control Release. 1998; 56(1-3):75-83. [PubMed: 9801431]

41. Miyazaki S, Suzuki S, Kawasaki N, Endo K, Takahashi A, Attwood D. In situ gelling xyloglucan formulations for sustained release ocular delivery of pilocarpine hydrochloride. Int J Pharm. 2001; 229(1-2):29-36. [PubMed: 11604255]

42. Takahashi A, Suzuki S, Kawasaki N, Kubo W, Miyazaki S, Loebenberg R, Bachynsky J, Attwood D. Percutaneous absorption of non-steroidal anti-inflammatory drugs from in situ gelling xyloglucan formulations in rats. Int J Pharm. 2002; 246(1-2):179-186. [PubMed: 12270620] 
43. Filion D, Lavertu M, Buschmann MD. Ionization and solubility of chitosan solutions related to thermosensitive chitosan/glycerol-phosphate systems. Biomacromolecules. 2007; 8(10):32243234. [PubMed: 17850110]

44. Ruel-Gariepy E, Chenite A, Chaput C, Guirguis S, Leroux J. Characterization of thermosensitive chitosan gels for the sustained delivery of drugs. Int J Pharm. 2000; 203(1-2):89-98. [PubMed: 10967431]

45. Chenite A, Chaput C, Wang D, Combes C, Buschmann MD, Hoemann CD, Leroux JC, Atkinson BL, Binette F, Selmani A. Novel injectable neutral solutions of chitosan form biodegradable gels in situ. Biomaterials. 2000; 21(21):2155-2161. [PubMed: 10985488]

46. Bush, JR.; Madhu, V.; Laurencin, CT.; Balian, G.; Nair, L. Thermosensitive chitosan as a matrix for the controlled delivery of biologically active molecules for bone repair. Salt Lake City, UT: American Institute of Chemical Engineers Annual Meeting; 2007.

47. Ruel-Gariepy E, Shive M, Bichara A, Berrada M, Le Garrec D, Chenite A, Leroux JC. A thermosensitive chitosan-based hydrogel for the local delivery of paclitaxel. Eur J Pharm Biopharm. 2004; 57(1):53-63. [PubMed: 14729080]

48. Ganji F, Abdekhodaie MJ, A R. Gelation time and degradation rate of chitosan-based injectable hydrogel. Journal of Sol-Gel Science and Technology. 2007; 42:47-53.

49. Kumar V, Lewis SA, Mutalik S, Shenoy DB, Venkatesh, Udupa N. Biodegradable microspheres of curcumin for treatment of inflammation. Indian J Physiol Pharmacol. 2002; 46(2):209-217. [PubMed: 12500496]

50. Truskey, GA.; Yuan, F.; Katz, DF. Transport Phenomena in Biological Systems. Upper Saddle River, New Jersey: Prentice Hall; 2003. p. 816

51. Peppel K, Crawford D, Beutler B. A tumor necrosis factor (TNF) receptor-IgG heavy chain chimeric protein as a bivalent antagonist of TNF activity. J Exp Med. 1991; 174(6):1483-1489. [PubMed: 1660525]

52. Edwards CK 3rd, Martin SW, Seely J, Kinstler O, Buckel S, Bendele AM, Ellen Cosenza M, Feige U, Kohno T. Design of PEGylated soluble tumor necrosis factor receptor type I (PEG sTNF-RI) for chronic inflammatory diseases. Adv Drug Deliv Rev. 2003; 55(10):1315-1336. [PubMed: 14499710]

53. Pan Ch J, Tang JJ, Weng YJ, Wang J, Huang N. Preparation, characterization and anticoagulation of curcumin-eluting controlled biodegradable coating stents. J Control Release. 2006; 116(1):4249. [PubMed: 17046093]

54. Yang X, Thomas DP, Zhang X, Culver BW, Alexander BM, Murdoch WJ, Rao MN, Tulis DA, Ren J, Sreejayan N. Curcumin inhibits platelet-derived growth factor-stimulated vascular smooth muscle cell function and injury-induced neointima formation. Arterioscler Thromb Vasc Biol. 2006; 26(1):85-90. [PubMed: 16239599]

55. Bisht S, Feldmann G, Soni S, Ravi R, Karikar C, Maitra A. Polymeric nanoparticle-encapsulated curcumin ("nanocurcumin"): a novel strategy for human cancer therapy. J Nanobiotechnology. 2007; 5:3. [PubMed: 17439648]

56. Molinaro G, Leroux JC, Damas J, Adam A. Biocompatibility of thermosensitive chitosan-based hydrogels: an in vivo experimental approach to injectable biomaterials. Biomaterials. 2002; 23(13):2717-2722. [PubMed: 12059021]

57. Thakkar H, Sharma RK, Mishra AK, Chuttani K, Murthy RS. Efficacy of chitosan microspheres for controlled intra-articular delivery of celecoxib in inflamed joints. J Pharm Pharmacol. 2004; 56(9):1091-1099. [PubMed: 15324477]

58. Lu JX, Prudhommeaux F, Meunier A, Sedel L, Guillemin G. Effects of chitosan on rat knee cartilages. Biomaterials. 1999; 20(20):1937-1944. [PubMed: 10514071]

59. Suh JK, Matthew HW. Application of chitosan-based polysaccharide biomaterials in cartilage tissue engineering: a review. Biomaterials. 2000; 21(24):2589-2598. [PubMed: 11071608] 

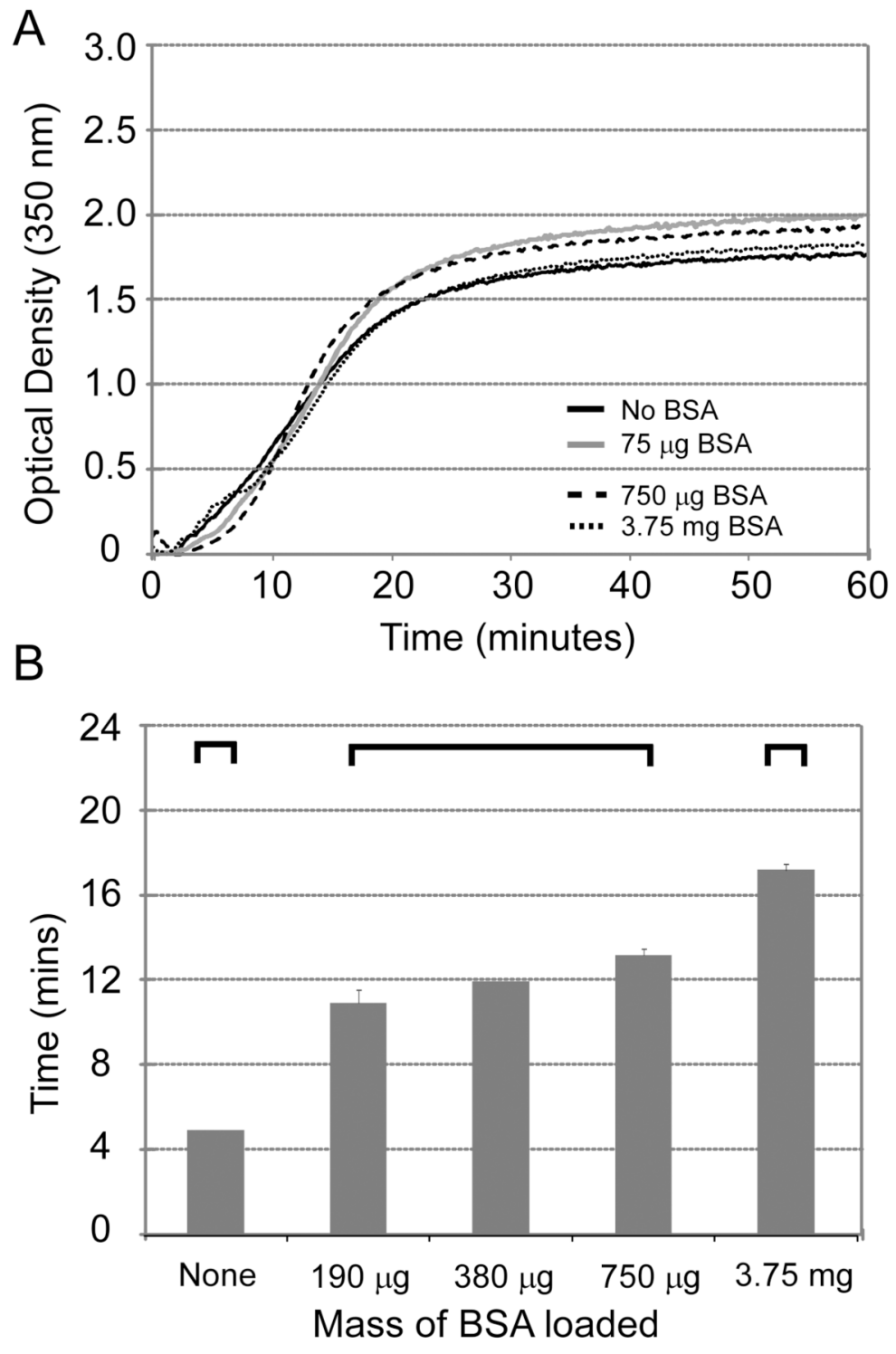

Figure 1.

Figure 1A The onset of turbidity in $1 \mathrm{~mL}$ chitosan-GP solutions raised to $37^{\circ} \mathrm{C}$ is not significantly affected by the addition of up to $3.75 \mathrm{mg}$ of BSA. Transition to $50 \%$ of maximal turbidity changes occurs between 13 and 15 minutes for all preparations. The chitosan content of these gels is $15 \mathrm{mg}$.

Figure 1B The thermogelling transition of chitosan-glycerophosphate as assessed by the gel-tipping technique demonstrates gradual prolongation of transition time with the inclusion of progressively higher amounts of BSA (ANOVA, $p<0.01$ ). Bracketed groups are not significantly different (Dunn's, $\alpha=0.05$ ). Data are shown for gelation time for varying amounts of added BSA (mean + s.e.m., $n=4)$. 


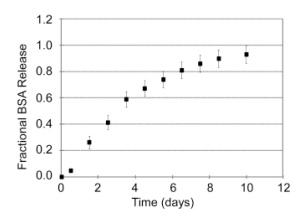

Figure 2.

Cumulative release (mean \pm s.e.m., $\mathrm{n}=4$ ) of BSA from the chitosan-GP gels was quantified using the bicinchoninic acid assay. Sustained release from these formulations was observed, with $50 \%$ of loaded BSA released at approximately 72 hours. 


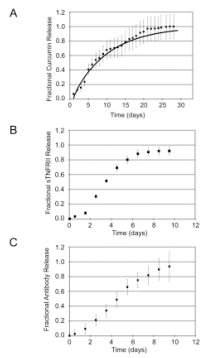

Figure 3.

Figure 3A Cumulative release (mean \pm s.e.m., $n=5$ ) of curcumin from the chitosan-GP gels was quantified using absorbance spectrophotometry. Sustained release from these formulations was observed, with $50 \%$ of loaded curcumin released at approximately 156 hours.

Figure 3B Cumulative release (mean \pm s.e.m., $n=4$ ) of sTNFRII from the chitosan-GP gels was quantified using an sTNFRII ELISA. Sustained release from these formulations was observed, with $50 \%$ of loaded sTNFRII released at approximately 84 hours.

Figure 3C Cumulative release (mean \pm s.e.m., $n=4$ ) of anti-TNF antibody from the chitosan-GP gels was quantified using a TNF $\alpha$-directed immunoassay. Sustained release from these formulations was observed, with $50 \%$ of loaded anti-TNF antibody released at approximately 108 hours. 


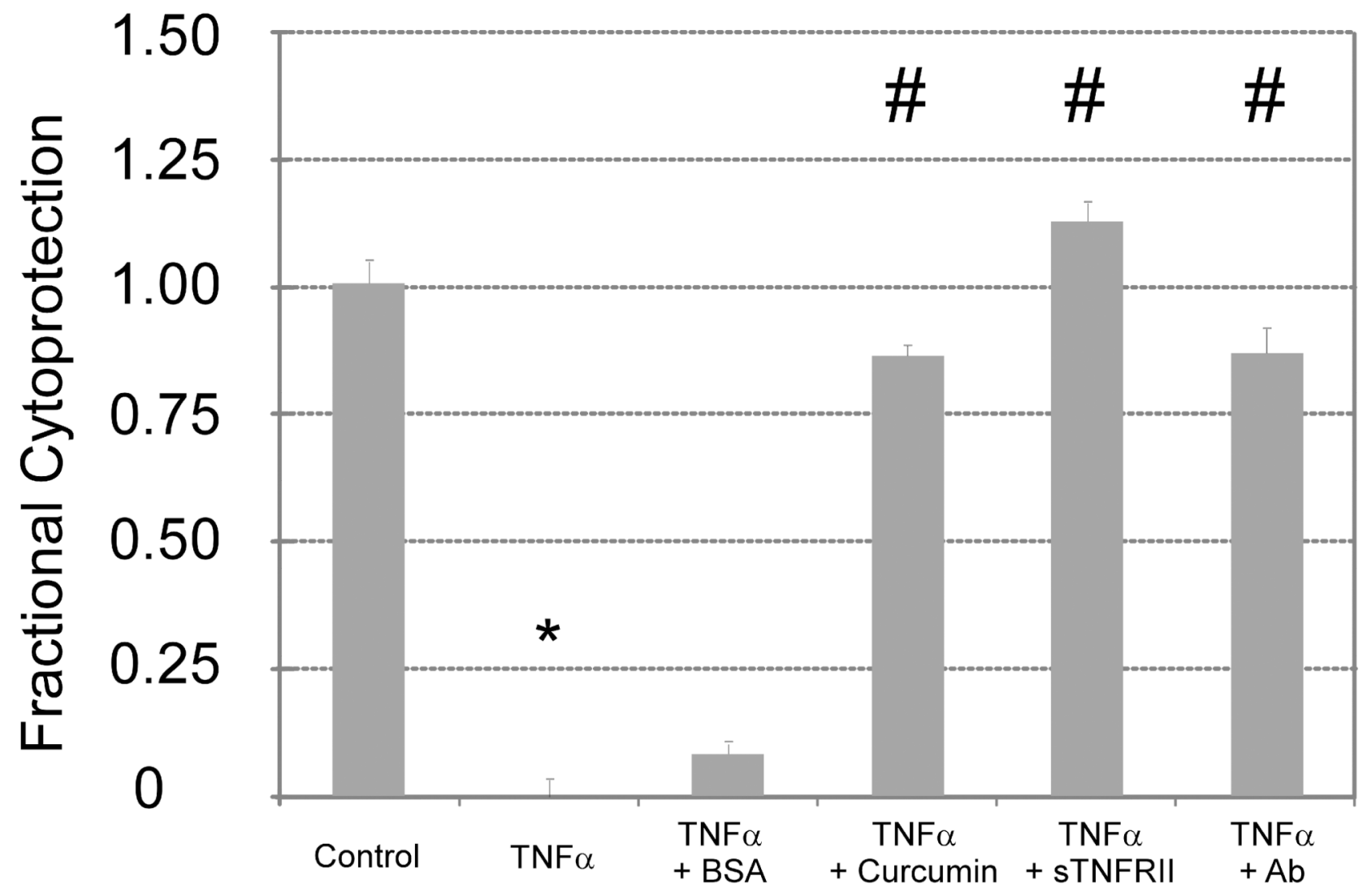

\section{Treatment}

Figure 4.

Antagonists of TNF $\alpha$ activity retain in vitro bioactivity following release from chitosan-GP gels (ANOVA, $\mathrm{p}<0.01$ ). Exposure of murine L929 fibrosarcoma cells to $0.25 \mathrm{ng} / \mathrm{mL} \mathrm{TNF} \alpha$ leads to a profound decrease (*, Dunn's, $\alpha=0.05$ ) in cell survival (mean \pm s.e.m., $n=8$ ). Cytoprotection was observed when cells were treated with supernatant containing curcumin, anti-TNF antibody, sTNFRII released from these gels (\#). This protective effect was not observed upon coincubation with BSA-containing supernatant released from BSA-loaded chitosan-GP gels. 